\title{
Correlation Study of AIOS (Acute IIIness Observation Scale) Score with Radiological Findings and Pulse Oximetry in Community-Acquired Pneumonia (Cap) Among Children Aged 2 To 59 Months
}

\author{
Pavan D. Kumar ${ }^{\circledR 1}$, Khaleelullah MD Shakil ${ }^{\circledR 2}$, Sreenivasa B. ${ }^{\circledR 3}$, Talatam Sivachand ${ }^{\odot 4}$ \\ ${ }^{1}$ Associate Professor, Department of Pediatrics, DM Wayanad Institute of Medical Sciences, Meppadi, Wayanad, Kerala, India, ${ }^{2}$ Assistant Professor, Department of \\ Pediatrics, Basaveshwara Medical College Hospital and Research Centre, Chitradurga, Karnataka, India, ${ }^{3}$ Professor, Department of Pediatrics, Basaveshwara Medical \\ College Hospital and Research Centre, Chitradurga, Karnataka, India, ${ }^{4}$ Senior Resident, Department of Pediatrics, Basaveshwara Medical College Hospital and Research \\ Centre, Chitradurga, Karnataka, India.
}

\section{Abstract}

Background: Community-acquired pneumonia (CAP) is one of the primary causes of mortality in infants and young children. Acute Illness Observation Score (AIOS) - act as the best and accurate indicator for the same. Hence in this study, AIOS was used to relate X-ray abnormalities and pulse oximeter finding for early assessment in children with ARI. Subjects and Methods: This was a descriptive epidemiological study conducted for a period of 24 months. Children aged from 2 months to 59 months who had symptoms and signs suggestive of pneumonia were involved in the study. Pulse oximetry reading on admission was noted. AIOS scoring is done on each subject. Chest X-ray was taken and interpreted. Results: The majority of patients fall in the age group of 2- 12 months $(57.2 \%)$. CXR showed abnormal radiological changes in $54.0 \%$, among them endpoint consolidation, was seen in $40.20 \%$ and infiltrates seen in $59.7 \%$. 67 patients had spo $2>92 \%$ at admission, among them $44(65.67 \%)$ had normal \& $23(34.32 \%)$ had abnormal chest X-ray. $57.3 \%(43 / 75)$ children with AIOS of $\leq 10$ had normal x-ray \& $42.66 \%$ $(32 / 75)$ had abnormal $x$-ray. AIOS with Spo2 reading showed a good correlation $(\mathrm{p}<0.05)$ indicating that high AIOS scores are associated with low SpO2 scores. Conclusion: This study shows that with the help of AIOS scoring, fair association with an initial pulse oximeter reading and X-ray abnormalities can be done which can be utilized as an early combining tool for risk assessment and management.

Keywords: AIOS scores, CAP, SPO2, X-ray abnormalities

Corresponding Author: Khaleelullah MD Shakil, Assistant Professor, Department of Pediatrics, Basaveshwara Medical College Hospital and Research Centre, Chitradurga, Karnataka, India.

E-mail: shakilmk56@gmail.com

Received: 02 September 2020

Revised: 18 October 2020

Accepted: 26 October 2020

Published: 28 December 2020

\section{Introduction}

Worldwide, respiratory diseases are a significant cause of morbidity in the pediatric age group. It is one of the most usual reasons with which parents bring their children to pediatric OPD as well as an emergency unit. ${ }^{[1]}$ The burden of ARI is significantly more in developing countries when compared to industrialized countries due to various reasons. In developing countries, the incidence of ARIs in children aged less than 5 years is about 0.29 episodes per child-year accounting for up to 151 million new episodes per year. ${ }^{[2]}$ Whereas in developed countries about 5 million new cases occur each year which is approximately 0.05 episodes per child year. ${ }^{[2]} 12-20$ of every 1000 children born per year succumb to death before 5 years of life. This shows that pneumonia accounts for about $21 \%$ of all deaths in these children. ${ }^{[3]}$ Hence it is important to formulate criteria for the effective and optimal management of Pneumonia in less developed countries.AIOS is a threepoint scale with a total score ranging from 6-30. It has 6 ordinal components. If the AIOS score is 10 or less than 10, the incidence of significant bacterial infection is less than 2$3 \%$, whereas the incidence rises to $26 \%$ for scores between $11-15$ and $92 \%$ for scores equal to 16 or more. ${ }^{[4]}$ Hence this score was used in the study to validate the correlation with radiological abnormalities and pulse oximetry reading in children with ARI. 


\section{Subjects and Methods}

The aims and objectives of this study are to correlate AIOS score with radiological findings and pulse oximetry in community-acquired pneumonia. This descriptive epidemiological study was conducted in a tertiary care DM Wayanad Medical college and hospital in Kerala for a period of 24 months from September 2017- September 2019. Children in the age group of 2 to 59 months who presented with symptoms suspicious of pneumonia were included in the study. Clinical features included are a fever with less than 3 days of duration, cough or difficult breathing, tachypnoea, stridor, grunting, chest retractions, lethargy, convulsions, inability to drink. Children who presented with symptoms and signs suggestive of pneumonia and satisfying the inclusion criteria were involved in the study. IMNCI classification which assesses the severity of illness was used to identify patients needing outpatient or inpatient management. AIOS scoring is done on each subject on day 1, day 2, day 5 by two persons simultaneously in a reasonably quiet state. Spo2 reading of all patients was recorded. At the time of initial assessment, vital signs and respiratory variables were recorded. Cultures of blood and urine, Chest X-ray PA view and complete blood count were done within $24 \mathrm{hrs}$ of admission. A radiologist who was blinded about the study was sought for reporting of Chest Xray. A total of 124 children were enrolled in the study. Cases excluded from the study were those presented with more than 2 weeks duration of illness, upper respiratory infections like acute pharyngitis with less severe respiratory symptoms and those with predominant wheeze as the chief complaint. Results were analyzed for the extent to which chest X-ray and pulse oximetry readings correlate to the AIOS score thereby indicating the severity of pneumonia.

\section{Statistical analysis \& Statistical methods}

Descriptive statistical analysis was carried out in the present study. Data entry was done in a Microsoft Excel sheet. Statistical significance was found using the chi-square test.

\section{Results}

After the exclusion of 28 children who had associated cardiac problems and positive for gastro-oesophageal reflux, 124 children were enrolled in the study. The demographic profile of the study group showed that the majority of them fall in the age group of 2- 12 months $(\mathrm{n}=71,57.2 \%)$ followed by 12 36 months $(n=48,38.7 \%)$. Among this group majority were males $(\mathrm{n}=80,64.5 \%)$.

Fever and cough were seen in almost all the children, whereas the history of Tachypnoea was seen in $98 \%$ of cases. Regarding danger symptoms, majority had lethargy $(\mathrm{n}=31$, $25 \%)$ while convulsion $(\mathrm{n}=5,4 \%)$ and grunt $(\mathrm{n}=7,5.6 \%)$ was least common. $48.38 \%$ of cases had a respiratory rate between
Table 1: Depicting Age and Sex Distribution among the Study Group:

\begin{tabular}{|llll}
\hline & & $\mathbf{n}$ & \% \\
Age & $2-12$ months & 71 & 57.2 \\
& $12-36$ & 48 & 38.7 \\
months & & \\
& $>36$ months & 5 & 4.0 \\
Sex & Male & 80 & 64.5 \\
& Female & 44 & 35.5 \\
\hline
\end{tabular}

51- 60 (48.38\%) which was the most common sign in the study group. Mild to moderate retraction was seen in $53.65 \%$ of cases and severe retraction in $32.6 \%$ of cases. Grunting and cyanosis were seen in $6.4 \%$ and $2.4 \%$ cases respectively.

\begin{tabular}{|c|c|c|c|}
\hline \multicolumn{2}{|l|}{ Signs } & \multirow{2}{*}{$\begin{array}{l}\text { Total } \\
39\end{array}$} & \multirow{2}{*}{$\begin{array}{l}\text { \% } \\
31.77\end{array}$} \\
\hline Respiratory & $40-50$ & & \\
\hline & $51-60$ & 60 & 48.38 \\
\hline & $>60$ & 15 & 12.09 \\
\hline \multicolumn{2}{|c|}{ Intercostal recession } & 56 & 45.16 \\
\hline \multirow[t]{2}{*}{$\begin{array}{l}\text { Sub coastal } \\
\text { recession }\end{array}$} & $\begin{array}{l}\text { Mild- } \\
\text { moderate }\end{array}$ & 66 & 53.20 \\
\hline & severe & 41 & 33.00 \\
\hline \multicolumn{2}{|l|}{ Grunt } & 8 & 6.4 \\
\hline \multicolumn{2}{|l|}{ Cyanosis } & 3 & 2.4 \\
\hline \multicolumn{2}{|l|}{ Lethargy } & 32 & 25.8 \\
\hline \multicolumn{2}{|l|}{ Convulsion } & 5 & 4 \\
\hline \multicolumn{2}{|c|}{ inability to drink } & 19 & 15.30 \\
\hline \multicolumn{2}{|c|}{$\begin{array}{l}\text { Abnormal Capillary refill } \\
\text { time }(>2 \mathrm{sec})\end{array}$} & 15 & 12.09 \\
\hline \multicolumn{2}{|c|}{ Decreased breath sounds } & 6 & 4.8 \\
\hline \multicolumn{2}{|c|}{ Bronchial breathing } & 7 & 5.6 \\
\hline \multicolumn{2}{|l|}{ Crepitations } & 113 & 91.12 \\
\hline \multicolumn{2}{|l|}{ Wheeze } & 32 & 25.80 \\
\hline \multirow[t]{2}{*}{ Vocal } & Decreased & 3 & 2.4 \\
\hline & increased & 3 & 2.4 \\
\hline
\end{tabular}

Pulse oximeters recording were taken in all children on days 1,2 and 5. 5.6\% (7/124) of cases had central cyanosis with Spo 2 below $85 \%$. Spo 2 recording of $>92$ was seen in $54.0 \%$ $(67 / 124)$ and the remaining being in between. The average pulse oximeter value on day 1 in the study sample was 92.9(SD-5.10).

In this study, $45.96 \%(57 / 124)$ had normal CXR findings and the remaining 54\% (67/124) had significant abnormalities. Endpoint consolidation was seen in $40.2 \%$ of cases while 


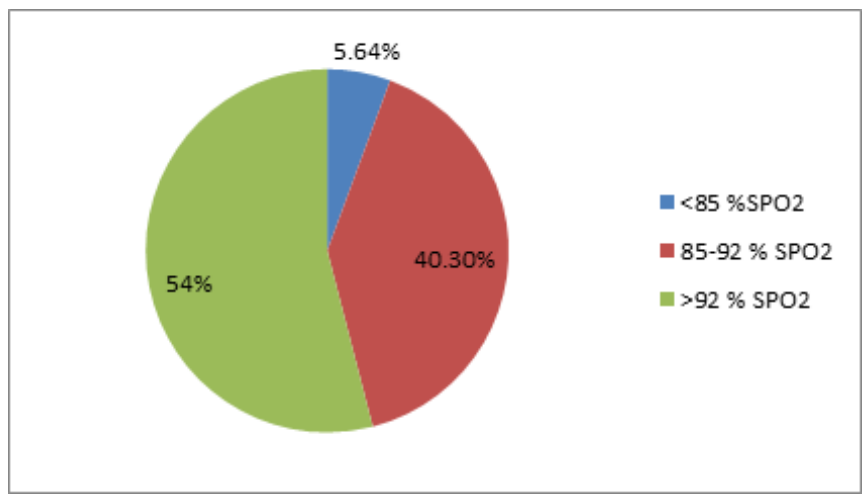

Figure 1: Depicting Spo2 Reading in the Study Population:

$59.7 \%$ had non-end point infiltrates which were the common X-ray abnormalities.

Spo 2 reading of $<92 \%$ at admission, predicted abnormal chest $\mathrm{x}$ - ray was seen in 44 out of 57 patients $(77.19 \%)$ \& normal in 12 out of 57 patients (21\%). 67 patients had spo $2>92$ at admission, among them $44(65.67 \%)$ had normal \& $23(34.32$ $\%$ ) had abnormal chest X-ray.

AIOS score more than 10 at the time of primary evaluation was seen in $40 \%$ of children with community-acquired pneumonia which was abnormal. The mean score for AIOS is 12.32 (SD-6.12). It highlights the magnitude of illness of children involved in this study.

\section{$\chi 2=7.68 \mathrm{P}=0.16$}

In our study, on comparing AIOS score with their radiologic finding, it was found that $57.3 \%(43 / 75)$ of children with AIOS of $\leq 10$ had normal x-ray \& $42.66 \%(32 / 75)$ had an abnormal x-ray. $47.6 \%(10 / 21)$ of children with AIOS of 11-15 had a normal x-ray. In AIOS score $>16,85.7 \%$ (24/28) children had abnormal $x$-ray and these results were statistically significant (P-value $<0.05$ ).

\section{P-value $<0.05$}

Relating children's AIOS score against their pulse ox meter recording on admission, severe hypoxemia associated with cyanosis $(\mathrm{SpO} 2<85)$ was observed in 7 children of which $85.7 \%$ (6) scored a high value on AIOS (AIOS $>16$ ) whereas $82.0 \%$ (55) of children scored normally on AIOS among the group of 67 with a spo $2>92$.

\section{$\mathrm{X} 2=85.4 \mathrm{P}=\mathbf{0 . 0 0 1}$}

\section{Discussion}

In underdeveloped and developing countries, Childhood pneumonia is one of the most common infective illnesses. It holds a pivotal role as it is one of the preventable causes of mortality in children. In comparison to the traditional history taking and physical examination which has poor sensitivity, our study showed that history and examination when combined with AIOS scoring have a higher sensitivity and correlation for serious illness. Among 124 children enrolled in this study, $45.9 \%(n=57)$ of patients had hypoxemia. This was similar to the study done by Salah et al, ${ }^{[5]}(42.7 \%)$ and Basnet $\mathrm{S}$ et al, ${ }^{[6]}(38.7 \%)$. In our study, the majority of them fall in the age group of 2- 12 months $(\mathrm{n}=71,57.2 \%)$. Studies were done by Reddaiah VP et al, ${ }^{[7]}(63.2 \%)$ and Sehgal V et al, ${ }^{[8]}(52.2 \%)$ also had a similar observation. Tachypnoea and chest retractions were found to be a distinct features in detecting pneumonia in a study conducted by Palafox $\mathrm{M}$ et

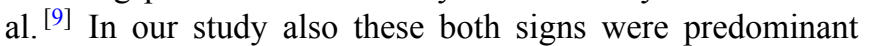
among the majority. Crepitation $(91.12 \%)$, abnormal breath sounds $(5.6 \%)$, wheeze $(25.80 \%)$, lethargy $(25.80 \%)$, CRT $>2 \sec (12.09 \%)$, cyanosis $(2.4 \%) \&$ grunt $(6.4 \%)$ were other associated signs in our study. In our study, CXR showed abnormal radiological changes in $54.0 \%$, among them endpoint consolidation was seen in $40.20 \%$ and infiltrates seen in $59.7 \%$. Spo 2 reading of $<92 \%$ at admission, predicted abnormal chest $x$-ray was seen in 44 out of 57 patients $(77.19 \%) \&$ normal in 12 out of 57 patients $(21 \%) .67$ patients had spo $2>92$ at admission, among them $44(65.67 \%)$ had normal \& $23(34.32 \%)$ had abnormal chest X-ray, this was in comparison with the study conducted by Cevey-Macherel M et al. ${ }^{[10]}$

AIOS score more than 10 at the time of primary evaluation was seen in $40 \%$ of children with community-acquired pneumonia which was abnormal. The mean score for AIOS is 12.32 (SD-6.12). It highlights the magnitude of illness of children involved in this study. This AIOS scoring system was studied. Bhavneet Barathi et al, ${ }^{[11]}$ for assessing its usefulness in managing severe childhood pneumonia5 in 2-59 months. In predicting abnormal chest X-ray, Sensitivity of AIOS score $>$ 11 was $77 \%$, Specificity was $48 \%$. $57.3 \%$ (43/75) children with AIOS of $\leq 10$ had normal x-ray \& 42.66\% (32/75) had abnormal x-ray. $47.6 \%$ (10/21) of children with AIOS of 1115 had a normal $x$-ray. In AIOS score $>16,85.7 \%(24 / 28)$ children had abnormal x-ray. In a study done by Murali BH et al, ${ }^{[12]}$ similar observations were noted with $77.5 \%$ of $\mathrm{x}$ rays being normal when the AIOS score was $<10$ in cases of community-acquired pneumonia. As AIOS scoring has a good correlation with X-ray abnormalities it can be utilized to decide on $\mathrm{X}$-ray evaluation and hence minimizing exposure to hazardous radiations in a child with pneumonia. AIOS scoring has a good association with initial pulse oximeter reading and decision regarding supplementation of oxygen. In this study, we found a good correlation between AIOS with Chest X-Ray $(p<0.05)$. AIOS with Spo2 reading showed a good correlation $(\mathrm{p}<0.05)$ indicating that high AIOS scores are associated with low $\mathrm{SpO} 2$ scores thereby denoting more 


\begin{tabular}{llll}
\hline \multicolumn{2}{l}{ Table 3: Depicting Radiologic Findings in the Study Population: } & & \\
\hline investigation & & $\mathbf{n}$ & \% \\
\hline CXR & abnormal & 67 & 54 \\
& normal & 57 & 45.9 \\
finding & Endpoint consolidation & 27 & 40.2 \\
& infiltrates & 40 & 59.7 \\
\hline
\end{tabular}

Table 4: Depicting the Correlation between X-Ray Findings and Pulse Oximetry:

\begin{tabular}{|c|c|c|c|c|c|c|c|}
\hline \multirow[t]{3}{*}{ CHEST $\mathrm{X}$ - } & \multicolumn{6}{|c|}{ SPO2 ON ADMISSION(n=124) } & \multirow[t]{2}{*}{ p-value } \\
\hline & $\geq 92(67)$ & & 85-9 & & $<\mathbf{8 5}(7$ & & \\
\hline & NO. & $\%$ & NO. & $\%$ & NO. & $\%$ & \\
\hline NORMAL & 44 & 65.6 & 11 & 22 & 2 & 28.5 & $<0.05$ \\
\hline ABNORMAL & 23 & 34.3 & 39 & 78.0 & 5 & 71.42 & \\
\hline
\end{tabular}

Table 5: Depicting AIOS Score Distribution in the Study Population:

\begin{tabular}{lllllll}
\hline Age & AIOS on day $\mathbf{1}$ & & & & & \\
& $\leq \mathbf{1 0}$ & $\mathbf{1 1 - 1 5}$ & $\mathbf{1 6}$ & \\
& $\mathbf{n}$ & $\mathbf{\%}$ & $\mathbf{n}$ & $\mathbf{\%}$ & $\mathbf{n}$ & $\mathbf{\%}$ \\
\hline 2-12 months & 39 & 54.9 & 14 & 19 & 18 & 26.8 \\
\hline 12- 36 m0nths & 32 & 68.4 & 7 & 14.7 & 8 & 16.8 \\
$>36$ months & 4 & 63.6 & 0 & 0 & 2 & 36.4 \\
\hline
\end{tabular}

Table 6: Depicting the co rrelation between AIOS scores with chest X-ray:

\begin{tabular}{lllllll|}
\hline Chest X-ray & AIOS score on day $\mathbf{1}$ & & & & \\
& $\leq \mathbf{1 0}$ & & $\mathbf{1 1 - 1 5}$ & & $\mathbf{1 6}$ & \\
& $\mathbf{n}$ & $\mathbf{\%}$ & $\mathbf{n}$ & $\mathbf{0}$ & $\mathbf{n}$ & $\mathbf{\%}$ \\
\hline abnormal & 32 & 47.7 & 11 & 16.4 & 24 & 35.8 \\
\hline normal & 43 & 75.4 & 10 & 17.5 & 4 & 7.01 \\
\hline
\end{tabular}

Table 7: Depicting the Correlation between AIOS Scores with Spo2 Reading:

\begin{tabular}{lllllll}
\hline SpO2 reading & \multicolumn{2}{l}{ AIOS score on day1 } & & & & \\
& $\leq \mathbf{1 0}$ & & $\mathbf{1 1 - 1 5}$ & $\mathbf{1 6}$ & $\mathbf{0}$ \\
& $\mathbf{n}$ & $\mathbf{\%}$ & $\mathbf{n}$ & $\mathbf{0}$ & $\mathbf{N}$ & $\mathbf{\%}$ \\
\hline$<85$ & 1 & 14.2 & 0 & 0 & 6 & 85.7 \\
$85-92$ & 19 & 38.0 & 13 & 26.0 & 18 & 36.0 \\
$>92$ & 55 & 82.0 & 8 & 11.9 & 4 & 5.97 \\
\hline
\end{tabular}

severe respiratory illness. Lazzerini $\mathrm{M}$ et al, ${ }^{[13]}$ in a systemic review and meta-analysis showed that in underdeveloped and developing countries hypoxemia is the key determinant in mortality in ARI in children. Therefore the significance of routine use of Pulse oximetry and accessibility to oxygen in reducing death rate is to be understood. Similarly, Zhang L et al, ${ }^{[14]}$ have also expressed that in developing countries there should be facilities for easy and quick access to pulse oximetry.

\section{Conclusion}

To conclude the AIOS score has good sensitivity in the pneumonia group but with a poor specificity. But in both the severe pneumonia group and in the very severe pneumonia group, it has good specificity and poor sensitivity in diagnosing pneumonia when compared with IMNCI. So IMNCI is still the superior sensitive tool in the classification of pneumonia. This 
study shows that the AIOS scoring has a fair association with initial pulse oximeter reading and decision regarding supplementation of oxygen. So it can be used as a tool to decide on providing oxygen to patients in resource-limited areas. AIOS scoring also has a good correlation with X-ray abnormalities so can be utilized to decide on X-ray evaluation and hence prevents preventing the unnecessary display of child presenting with ARI to radiations.

\section{References}

1. Armon K, Stephenson T, Gabriel V. Determining the common medical problems presenting to an accident and emergency department. Arch Dis Child. 2001;84(5):390-392. Available from: http://dx.doi.org/10.1136/adc.84.5.390.

2. Rudan I, Boschi-Pinto C, Biloglav Z, Mulholland K, Campbell H. Epidemiology and etiology of childhood pneumonia. Bull World Health Organ. 2008;86(5):408-424. Available from: https://doi.org/10.2471/blt.07.048769.

3. Williams BG, Gouws E, Boschi-Pinto C, Bryce J, Dye C. Estimates of world-wide distribution of child deaths from acute respiratory infections. The Lancet Infectious Diseases. 2002;2(1):25-32. Available from: https://dx.doi.org/10.1016/ s1473-3099(01)00170-0.

4. Bharti B, Bharti S, Verma V. Role of Acute Illness Observation Scale (AIOS) in managing severe childhood pneumonia. Indian J Pediatr. 2007;74(1):27-32. Available from: https://dx.doi. org/10.1007/s12098-007-0022-1.

5. Salah E, Algasim S, Mhamoud A, Husian N. Prevalence of hypoxemia in under-five children with pneumonia in an emergency pediatrics hospital in Sudan. Indian Journal of Critical Care Medicine. 2015;19(4):203-207. Available from: https://dx.doi.org/10.4103/0972-5229.154549.

6. Basnet S, Adhikari RK, Gurung CK. Hypoxemia in children with pneumonia and its clinical predictors. The Indian Journal of Pediatrics. 2006;73(9):777-781. Available from: https://dx. doi.org/10.1007/bf02790384.

7. Reddaiah VP, Kapoor SK. Acute respiratory infections in under five. Indian J Community Med. 1995;20:1-4.

8. Sehgal V, Sethi, Sachdev H, Satyanarayana. Predictors of mortality on subjects hospitalized with acute lower respiratory tract infections. Indian Pediatr. 1997;34(3):213-222.
9. Palafox M. Diagnostic value of tachypnoea in pneumonia defined radiologically. Arch Dis Child. 2000;82(1):41-45. Available from: https://dx.doi.org/10.1136/adc.82.1.41.

10. Cevey-Macherel M, Galetto-Lacour A, Gervaix A, Siegrist CA, Bille J, Bescher-Ninet B, et al. Etiology of community-acquired pneumonia in hospitalized children based on WHO clinical guidelines. Eur J Pediatr. 2009;168(12):1429-1436. Available from: https://dx.doi.org/10.1007/s00431-009-0943-y.

11. Bhavneet Bharti et al AIOS in managing severe childhood pneumonia. Indian Jou of Pedi. 2007;74:27-32.

12. H MB, Mulage L. AIOS v/s I MNCI IN COMMUNITY ACQUIRED PNEUMONIA. J Evol Med Dent Sci . 2014;3(13):3260-3266. Available from: https://dx.doi.org/10. 14260/jemds/2014/2277.

13. Lazzerini M, Sonego M, Pellegrin MC. Hypoxaemia as a Mortality Risk Factor in Acute Lower Respiratory Infections in Children in Low and Middle-Income Countries: Systematic Review and Meta-Analysis. PLOS One. 2015;10(9):e0136166e0136166. Available from: https://dx.doi.org/10.1371/journal. pone. 0136166 .

14. Zhang L, Mendoza R, Santos JC, Lau J. Accuracy of symptoms and signs in predicting hypoxemia among young children with acute respiratory infection: a meta-analysis. Int J Tuberc Lung Dis. 2011;15(3):317-342.

Copyright: (C) the author(s), 2020. It is an open-access article distributed under the terms of the Creative Commons Attribution License (CC BY 4.0), which permits authors to retain ownership of the copyright for their content, and allow anyone to download, reuse, reprint, modify, distribute and/or copy the content as long as the original authors and source are cited.

How to cite this article: Kumar PD, Shakil KMD, B. S, Sivachand T. Correlation Study of AIOS (Acute Illness Observation Scale) Score with Radiological Findings and Pulse Oximetry in Community-Acquired Pneumonia (Cap) Among Children Aged 2 To 59 Months. Asian J. Clin. Pediatr. Neonatol. 2020;8(4):1923.

DOI: dx.doi.org/10.47009/ajcpn.2020.8.4.5

Source of Support: Nil, Conflict of Interest: None declared. 